\title{
Correction to: Tissue Resistance during Large-Volume Injections in Subcutaneous Tissue of Minipigs
}

Andrea Allmendinger ' Stefan Fischer '

Published online: 30 November 2020

(C) Springer Science+Business Media, LLC, part of Springer Nature 2020

\section{Correction to: Pham Res (2020) 37: 184}

https://doi.org/ I 0. 1007/s I I 095-020-02906-9

Table 2 of the article 'Tissue Resistance during Large-Volume Injections in Subcutaneous Tissue of Minipigs' encountered formatting errors in the (original) pdf version with misplacement of text and columns. The pdf version of the article was updated to correct for formatting issues. The online version was correct.

The online version of the original article can be found at https://doi.org/l 0. | 007/s | | 095-020-02906-9

Andrea Allmendinger

andrea.allmendinger.aal@roche.com

Pharmaceutical Development \& Supplies Biologics Europe, F.

Hoffmann-La Roche Ltd, Grenzacherstrasse 124,

4070 Basel, Switzerland 


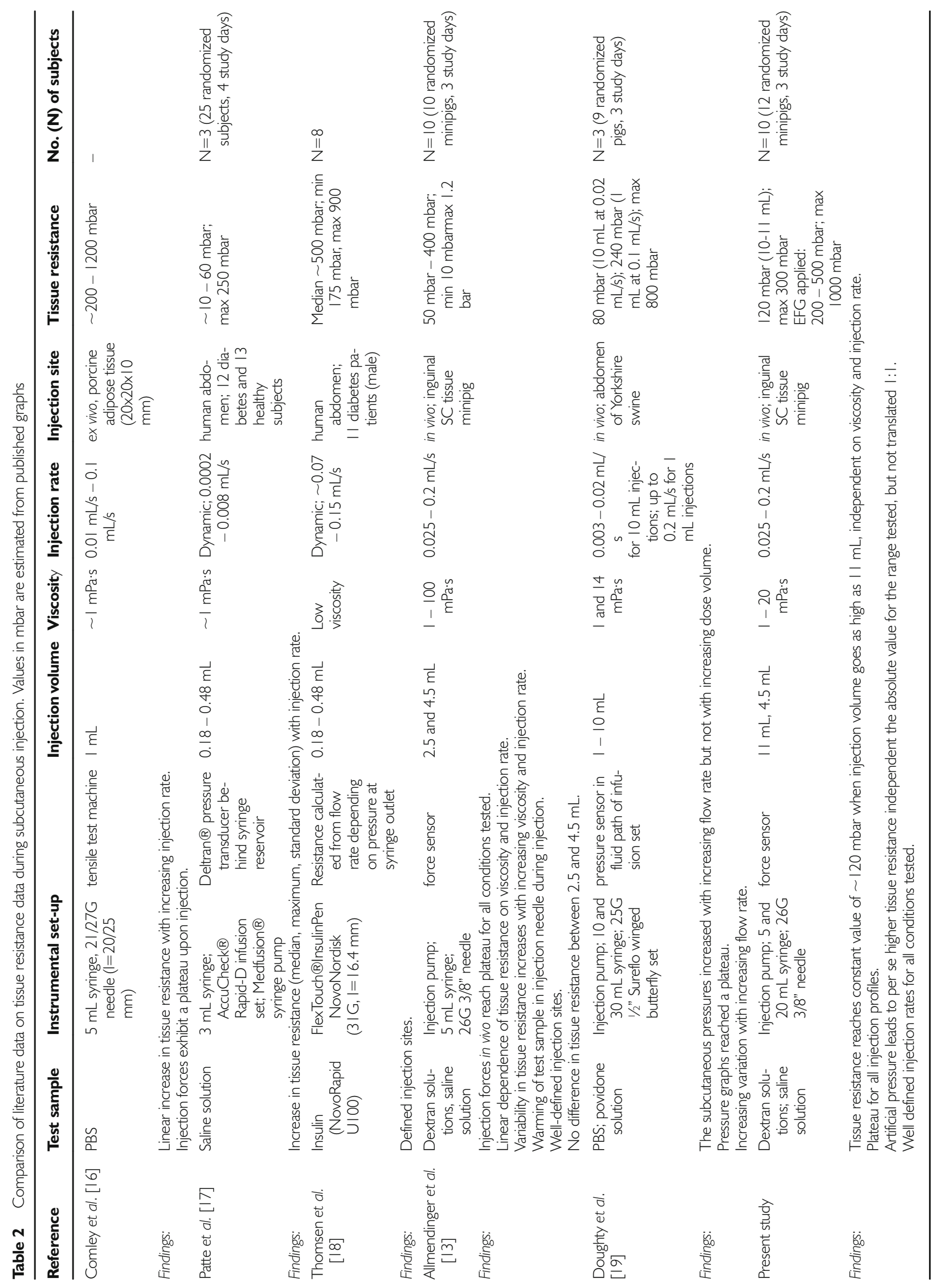

